\title{
Multiple Slip and Inspiration Effects on Hydromagnetic Casson Fluid in a Channel with Stretchable Walls
}

\author{
Bandaru Mallikarjuna $^{1 *}$, Sadhu Ramprasad ${ }^{2}$, Yathiraju Sudheer Kalyan Chakravarthy ${ }^{2}$ \\ ${ }^{1}$ Department of Mathematics, BMS College of Engineering, Bangalore, Affiliated to VTU, Belagavi 560019, India \\ ${ }^{2}$ Department of Mathematics, M.S. Ramaiah Institute of Technology, Bangalore-54, Affiliated to VTU, Belagavi 560054, India
}

Corresponding Author Email: mallikarjunab.maths@bmsce.ac.in

https://doi.org/10.18280/ijht.380407

Received: 26 January 2020

Accepted: 20 November 2020

\section{Keywords:}

multiple slips, stretchable walls, Casson fluid, suction/injection, magnetics field

\begin{abstract}
Increasingly innovatory techniques are being developed for the manufacturer of coated sheets. Magnetite non-Newtonian fluids have been shown to exhibit stretchable wall slip, which arises due to non-adherence of the non-Newtonian fluid to the boundary. Motivated by the physical nature of the magnetic non-Newtonian fluid in manufacturing transport phenomena, we develop a model to analyze the collective influence of velocity and thermal slips, radiative heat flux effects on fluid and heat transport phenomena in magnetic nonNewtonian fluid flow in a channel with stretchable walls. Governing equations are nondimensionalized and solved numerically. Grid independence test has been performed and then compared with existing literature in limiting cases. Results are discussed with the aid of graphs for the sway of several physical parameters, Casson parameter, Magnetic parameter, Thermal radiation parameter on fluid velocity, as well as temperature profiles for different cases: No-slip, only first-order slip, and first and second-order slips.
\end{abstract}

\section{INTRODUCTION}

A fluid whose viscosity varies non-linearly based on applied stress or force is known as non-Newtonian. The behavior of Newtonian fluids like water can be described exclusively by temperature and pressure. However, the physical behavior of non-Newtonian fluid depends on the forces acting on it. Latterly, the non-Newtonian fluid flows earned a great interest and give more prominence to several researchers because of its industrial and practical applications such as the food industry, pharmaceutical industries, ink-jet pointing, polymer processing, blood circulatory system, heat exchangers, electronic packaging, and so on. Its importance is also seen in enhanced oil recovery, hot rolling, solar collectors, the manufacturing process of coated sheets, plastic polymers, blood, gum solutions, starch suspensions, wet sand, tomato ketchup, and toothpaste.

One of the essential classes of non-Newtonian fluid flows is a Casson fluid model. Chocolate, concentration juices, honey, jelly, and tomato sauce, soap are a few examples of the Casson fluid. Casson fluid has significant applications in food processing, metallurgy, drilling operations, and bioengineering operations. Casson [1] was the first investigator who introduced the Casson fluid model. Many researchers [27] have deliberated the boundary layer analysis of the Casson Fluid. Hayat et al. [8] explained the flow of mixed convection stagnation point of Casson fluid over the stretching sheet and studied the influence of convective boundary conditions. Boundary layer flow of a Casson fluid over an exponentially permeable shrinking sheet has been inspected by Nadeem et al. [9]. Bhattacharyya et al. [10] have considered the existence of wall mass transfer on MHD boundary layer flow of nonNewtonian Casson fluid stretching/shrinking sheet. Nadeem et al. [11] have considered MHD Casson fluid flow in two lateral directions past a porous linear stretching sheet. Bhattacharyya [12] has examined the boundary layer stagnation-point flow of Casson fluid and heat transfer over a shrinking/stretching sheet. Mukhopadhyay [13] has deliberated the heat transfer analysis of a Casson fluid over a stretching surface in the presence of suction/injection. Parmanik [14] have studied the heat transfer of a Casson fluid with the effect of suction/injection on the exponential stretching surface. Makanda [15] has explained two-dimensional Casson fluid flow in the existence of a magnetic field in porous media over a stretching surface. Khan et al. [16] have discussed the heat effect based on the resistive force of the electromagnetic origin of MHD Casson fluid flow over a stretching sheet. Das et al. [17] have considered the velocity and thermal slip and studied the entropy generation homogeneous-heterogeneous reaction of Casson fluid over the stretching sheet. Nagendramma et al. [18] studied the MHD convective flow of Casson nanofluid from a slandering surface with Cattaneo-Christove heat flux. Hamid et al. [19] studied the significance of a uniform magnetic field on Casson fluid over a stretching sheet and investigated thermal radiation effects on the dual solution of Casson fluid.

Sometimes no-slip condition at the boundary does not hold and hence requires it is replaced by partial slip. Especially noslip condition is meager for most non-Newtonian fluids. The fluids having the boundary slip have copious applications in engineering and technological problems like polishing of artificial valves and cavities, fluid flow and heat transfer in microflow devices and rarified gas studies, and so on. Mahantesh et al. [20] investigated numerically fluid flow over a stretching sheet with a second-order slip, and succinctly explained that the first order, as well as second-order slip, influence the fluid flow. Rosca and Pop [21] discussed the fluid flow in a shrinking or stretching sheet with a velocity slip of second order. Mansur and Ishak [22] under the various slip 
boundary conditions have deliberated the MHD boundary layer nanofluid flow numerically on stretching/shining sheet. Zhu et al. [23] implemented the Homotopy analysis method to investigate heat transfer in water-based nanofluid under the influence of second-order slip. Hsiao [24] examined the mixed convection of heat and mass transfer over a slip boundarystretching surface of a nanofluid under the influence of heat suction/injection. Shashikumar et al. [25] numerically scrutinized the effect of slip velocity of second-order under the influence of non-linear thermal radiation. Rosca et al. [26] studied numerically flow through the sheet with the secondorder slip. They obtained dual solutions. Balaankireddy et al. [27] developed a mathematical model to study first-order slip double-diffusive flow of a Casson fluid past an inclined stretching surface. They concluded that this model could get multiple solutions. Recently, Vishnu Ganesh et al. [28] examined numerically the effect of velocity as well as a thermal slip of second-order on the convective flow of a Newtonian fluid through a stretching surface. Shahid et al. [29] studied first order multiple slip effects on MHD buoyant flow of nanofluid in a stretching sheet under chemical and thermal radiation effect. Hayat et al. [30] studied two dimensional nonDarcy flow of nanofluid over a curved stretching sheet under partial slip effect. Daniel et al. [31] studied the combined influence of viscous dissipation, chemical reaction, thermal radiation on MHD nanofluid past a stretching sheet under slip effect.

Fluid flow in a channel with stretching walls under the influence of heat transfer has attracted many researchers due to the diverse range of applications, various fields like petroleum supplies, separation process in chemical industries and etc. Misra et al. [32] examined the impact of heat transfer analytically in a channel with stretching walls and concluded that the backflow is observed near the central line of the channel. MHD flow and heat transfer of a non-Newtonian fluid in a stretching walled channel have been analyzed by Misra et al. [33]. They implemented a finite difference scheme to obtain numerical results. Ramanamurthy et al. [34] have examined the unsteady peristaltic flow of a viscous fluid in the 2-dimensional curved channel and explained the volumetric flow rate and average velocity of fluid particles are same at the walls. Ghosh et al. [35] studied heat transfer numerically in a channel with stretching walls under the influence of viscous and Ohmic dissipation. Sarojamma and Vasundhara [36] inscribed an article on hydro-magnetic non-Newtonian fluid over a channel with heat and mass transfer. Syed et al. [37] interpreted MHD of the flow of water-based nanofluids in a non-parallel stretchable channel and numerically discussed the results under the effect of various parameters on velocity and temperature profiles. Rauf et al. [38] developed a numerical model to investigate buoyancy-driven micro nanofluid in a stretchable channel under the influence of the magnetic field. Raza et al. [39] reported a numerical solution of a nanofluid through a channel under the influence of velocity and thermal slip effects. Reza et al. [40] investigated velocity and temperature slip effects of first order under the influence of magnetic field numerically. Kezzar et al. [41] used numerical and semi analytical method to study the combined influence of radiation and Hartmann on convective flow of a $\mathrm{Fe}_{3} \mathrm{O}_{4}$ nanofluid in a non-parallel stretchable wall. Zohra et al. [42] developed bio-nano transport model to investigate convective magnetohydrodynamic flow of a micropolar fluid under double diffusion effect with first order slip conditions.
With the available literature as mentioned above it is keenly observed that researchers have not considered second order velocity and thermal slip effects to study the fluid characteristics in fully developed flow channels with stretchable walls even it is more prominent phenomena in industrial and engineering fields like heat transfer flow in micro flow devices, rarified gas studies, polishing of artificial valves and cavities and etc. To fill this gap authors aimed to investigate the influence of second order velocity and thermal slip effects on MHD flow of non-Newtonian fluid in a channel with stretchable walls.

\section{MODEL OF THE PROBLEM}

Consider steady two dimensional viscous incompressible laminar flow of Casson fluid, which is electrically conducted in a channel bounded by stretching walls. Model of the problem shown in Figure 1, $x$-axis is along the direction of flow, and the $y$-axis is perpendicular to the channel. The upper and lower walls of the channel are designated at $y= \pm a$ and

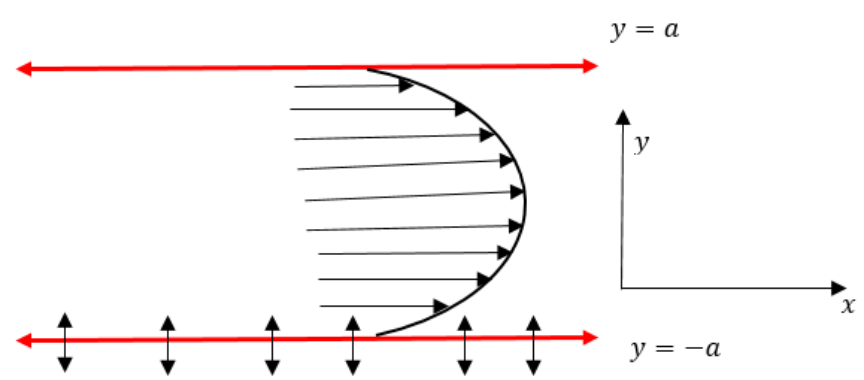

Figure 1. Physical configuration and coordinate system

Governing equations for the fluid model and magnetic field are:

$$
\begin{gathered}
\frac{\partial V}{\partial t}+\nabla \cdot(\rho V)=0 \\
\rho\left(\frac{\partial V}{\partial t}+V . \nabla V\right)=-\nabla P+\nabla \cdot \tau_{i j}+f
\end{gathered}
$$

Maxwell equations are:

$$
\nabla \cdot \bar{B}=0, \nabla \times \bar{B}=0, \nabla \times \bar{E}=0
$$

Ohm's law is:

$$
\bar{J}=\sigma(\bar{E}+V \times \bar{B})
$$

where, $V$ is the fluid velocity, $\rho$ is fluid density, $\bar{B}$ is the total magnetic field and $\bar{B}=\overline{B_{0}}+\bar{b}, \bar{b}$ is the induced magnetic field which is negligible and $f$ is the body force

$$
f=\bar{J} \times \bar{B}=\sigma\left(\left(V \times \bar{B}_{0}\right) \times \bar{B}_{0}\right)=-\sigma B_{0}^{2} u
$$

The rheological model of Casson [1] fluid is defined as 


$$
\tau_{i j}=\left\{\begin{array}{l}
2\left[\mu_{B}+\left(\frac{p_{y}}{\sqrt{2 \pi}}\right)\right] e_{i j}, \pi>\pi_{c} \\
2\left[\mu_{B}+\left(\frac{p_{y}}{\sqrt{2 \pi_{c}}}\right)\right] e_{i j}, \pi_{c}>\pi
\end{array}\right.
$$

where, $\tau_{i j}$ denotes Cauchy stress tensor, $\mu_{B}$ is dynamic viscosity of the Casson fluid, $\pi=e_{i} e_{j}$ is the square of components of the strain rate, $p_{y}$ denotes yield stress of the fluid and $\pi_{c}$ is the critical value of $\pi$.

Using (5) and (6), governing equations becomes [43, 44]:

$$
\begin{gathered}
\frac{\partial u}{\partial x}+\frac{\partial u}{\partial y}=0 \\
u \frac{\partial u}{\partial x}+v \frac{\partial u}{\partial y}=-\frac{1}{\rho} \frac{\partial p}{\partial x}+v\left(1+\frac{1}{\beta}\right) \frac{\partial^{2} u}{\partial y^{2}}-\frac{\sigma B_{0}^{2} u}{\rho} \\
u \frac{\partial v}{\partial x}+v \frac{\partial v}{\partial y}=-\frac{1}{\rho} \frac{\partial p}{\partial y}+v\left(1+\frac{1}{\beta}\right) \frac{\partial^{2} v}{\partial y^{2}}
\end{gathered}
$$

Boundary conditions

$$
\begin{gathered}
u=b x+\left(1+\frac{1}{\beta}\right)\left(s 1 \frac{\partial u}{\partial y}+s 2 \frac{\partial^{2} u}{\partial y^{2}}\right), v=-v_{w} \text { at } y=-a \\
u=b x-\left(1+\frac{1}{\beta}\right)\left(s 1 \frac{\partial u}{\partial y}+s 2 \frac{\partial^{2} u}{\partial y^{2}}\right), v=0 \text { at } y=a
\end{gathered}
$$

where, $\mathrm{b}$ is constant. For positive and negative value of $b$ stands for stretching and shrinking of the channel walls and for $b=0$ stands for flat walls. This problem is restricted to stretching walls of the channel.

Governing equation for energy is:

$$
u \frac{\partial T}{\partial x}+v \frac{\partial T}{\partial y}=\frac{k}{\rho c_{p}} \frac{\partial^{2} T}{\partial y^{2}}-\frac{1}{\rho c_{p}} \frac{\partial q_{r}}{\partial y}
$$

with associated boundary conditions

$$
\begin{aligned}
& T=T_{1}+s 3 \frac{\partial T}{\partial y}+s 4 \frac{\partial^{2} T}{\partial y^{2}} \quad \text { at } y=-a \\
& T=T_{2}-s 3 \frac{\partial T}{\partial y}-s 4 \frac{\partial^{2} T}{\partial y^{2}} \quad \text { at } \quad y=a
\end{aligned}
$$

Here,

$$
q_{r}=\frac{-4 \sigma^{*}}{3 k^{*}} \frac{\partial T^{4}}{\partial y}
$$

is the radiative heat flux which is used according to Rosseland approximation. Where $\sigma^{*}$ is the Stefen-Boltzman constant and $k^{*}$ is the mean absorption coefficient, as we are assuming the temperature difference is much small within the flow region, $T^{4}$ can be written as a first degree polynomial in temperature. By Taylor's series $T^{4}$ can be expanded about $T_{r}$, is the reference temperature of the fluid and neglecting higher order terms, we get

$$
T^{4} \cong 4 T_{r}^{3} T-3 T_{r}^{4}
$$

Introducing the similarity transformations

$$
\begin{aligned}
& \eta=\frac{y}{a}, u=b x f^{\prime}(\eta), v=-a b f(\eta), \\
& \theta=\frac{T-T_{2}}{T_{1}-T_{2}}, \phi=\frac{C-C_{2}}{C_{1}-C_{2}}
\end{aligned}
$$

to non-dimensionalize the Eqns. (7) to (12), by making use of (13) and (14) we get

$$
\begin{gathered}
\left(1+\frac{1}{\beta}\right) f^{i v}-\operatorname{Re}\left(f^{\prime} f^{\prime \prime}-f f^{\prime \prime \prime}\right)-M^{2} f^{\prime \prime}=0 \\
(1+R d) \theta^{\prime \prime}+\operatorname{Re} \operatorname{Pr} \theta^{\prime} f=0
\end{gathered}
$$

and conditions are:

$$
\begin{aligned}
& f^{\prime}(-1)=1+\left(1+\frac{1}{\beta}\right)\left(\lambda_{1} f^{\prime \prime}(-1)+\lambda_{2} f^{\prime \prime \prime}(-1)\right), \\
& f(-1)=\lambda, \theta(-1)=1+\delta_{1} \theta^{\prime}(-1)+\delta_{2} \theta^{\prime \prime}(-1) \\
& f^{\prime}(1)=1-\left(1+\frac{1}{\beta}\right)\left(\lambda_{1} f^{\prime \prime}(1)+\lambda_{2} f^{\prime \prime \prime}(1)\right), \\
& f(1)=0, \theta(1)=1-\delta_{1} \theta^{\prime}(1)-\delta_{2} \theta^{\prime \prime}(1)
\end{aligned}
$$

where, $\beta=\mu_{B} \frac{\sqrt{2 \pi_{c}}}{p_{y}}$ is the Casson parameter, $R e=\frac{a^{2} b}{v}$ is the Reynolds number, $R d=\frac{16 \sigma^{*} T_{\infty}{ }^{3}}{3 k k^{*}}$ is the Radiation parameter, $S c=\frac{v}{D}$ is the Schmidt number, $\operatorname{Pr}=\frac{\mu c_{p}}{k}$ is the Prandtl number, $M^{2}=\frac{\sigma}{\mu} B_{0}{ }^{2} a^{2}$ is the magnetic parameter, $\lambda=\frac{v_{w}}{a b}$ is the suction or injection parameter, $\lambda_{1}=\frac{s 1}{a}, \lambda_{2}=\frac{s 2}{a^{2}}$ are first and second order hydrodynamic slip conditions respectively along walls and $\delta_{1}=\frac{s 3}{a}, \delta_{2}=\frac{s 4}{a^{2}}$ are first and second order thermal slip conditions respectively along walls

The quantities of the physical interest are Skin friction and Nusselt number which are given by respectively

$$
C_{f}=\frac{\tau_{w}}{\frac{\mu b x}{a}} \text { and } N u=\frac{q_{w}}{\frac{k}{a}\left(T_{1}-T_{2}\right)}
$$

where, $\tau_{w}=\left(\mu_{B}+\frac{p_{y}}{\sqrt{2 \pi_{c}}}\right)\left(\frac{\partial u}{\partial y}\right)_{y= \pm a}$ and $q_{w}=k\left(\frac{\partial T}{\partial y}\right)_{y= \pm a}$.

In non-dimensional skin friction coefficient and rate of heat transfer (Nusselt number) are given by

$$
C_{f}=\left(1+\frac{1}{\beta}\right) f^{\prime \prime}( \pm 1) \text { and } N u=\theta^{\prime}( \pm 1)
$$




\subsection{Numerical procedure}

A set of Eqns. (16) and (17) with boundary conditions (18) are non-linear coupled differential equations, and it isn't easy to solve analytically. Therefore, numerical technique, namely, shooting technique $[45,46]$, is used as follows. First rewrite Eqns. (16) and (17) as a system of first-order equations by assuming $f=f(1), f^{\prime}=f(2), f^{\prime \prime}=f(3), f^{\prime \prime \prime}=f(4), \theta=$ $f(5), \theta^{\prime}=f(6)$ then

$$
\frac{d}{d \eta}\left[\begin{array}{c}
f(1) \\
f(2) \\
f(3) \\
f(4) \\
f(5) \\
f(6)
\end{array}\right]=\left[\begin{array}{c}
f(2) \\
f(3) \\
f(4) \\
{\left[\begin{array}{c}
-2 \operatorname{Re} f(2) f(3) \\
\left(1+\frac{1}{\beta}\right) \\
+\operatorname{Re}\left(\begin{array}{c}
f(1) f(4) \\
+f(2) f(3)
\end{array}\right) \\
+M^{2} f(3) \\
f(6) \\
\frac{-1}{(1+R d)}[\operatorname{Re} \operatorname{Pr} f(6) f(1)
\end{array}\right]}
\end{array}\right]
$$

Eq. (21) is a boundary value problem in vector form $[f(1), f(2), f(3), f(4), f(5), f(6)]$ with initial conditions at $f(1), f(2)$ and $f(5)$. Integrate eqn. (21) using Runge Kutta $4^{\text {th }}$ order by choosing initial conditions which are not provided in (18) are assumed as $f(3)(-1)=0.1, f(4)(-1)=0.2$, and $f(6)(-1)=0.3$. The obtained results at the other end are compared with given results (Eq. (18)). As observed more difference, Newton Raphson method is used to identify and suitable initial conditions instead of choosing randomly and then integrated Eq. (21).

\subsection{Grid independence test}

To verify the numerical technique, grid independence test has been performed. Step size $\Delta \eta$ is chosen as $0.1,0.01,0.001$, and 0.0001 and calculated skin friction and Nusselt number at the lower wall, as shown in Table 1. Table 1 shows that at $\Delta \eta=0.001$ values are getting $10^{-10}$ accuracy, and therefore same $\Delta \eta$ value is used throughout calculations.

Table 1. Skin friction and Nusselt number at lower wall for different $\Delta \eta$ values

\begin{tabular}{|c|c|c|}
\hline$\Delta \eta$ & $f^{\prime \prime}(-1)$ & $\theta^{\prime}(-1)$ \\
\hline 0.1 & -2.792767519138022 & 0.491380402584558 \\
\hline 0.01 & -2.792762766914234 & 0.491380812889240 \\
\hline 0.001 & -2.792762762143308 & 0.491380813262013 \\
\hline 0.0001 & -2.792741225653067 & 0.491378771808718 \\
\hline 0.00001 & -2.792741225653959 & 0.491378771808828 \\
\hline
\end{tabular}

\subsection{Code validation}

To validate the present results compared with published results by Reza et al. [40] for $M^{2}=0.5, \operatorname{Re}=2, \operatorname{Pr}=6.2, \lambda_{1}=0.1$, $\lambda_{2}=0.2, \lambda=0.5$ without radiation parameter and second order slips, Ashraf et al. [43] for $M^{2}=200, \operatorname{Re}=50, \operatorname{Pr}=2.5$ without slip conditions, radiation, and suction parameter as shown in
Table 2. From this Table 2 we conclude that present results are correlated with existing results in limiting cases.

Table 2. Comparison results of skin friction and Nusselt number along lower wall

\begin{tabular}{cccccc}
\hline \multicolumn{2}{c}{ Present results } & \multicolumn{2}{c}{ Ashraf et al. [43] } & \multicolumn{2}{c}{ Reza et al. [40] } \\
\hline$f^{\prime \prime}(-1)$ & $\theta^{\prime}(-1)$ & $f^{\prime \prime}(-1)$ & $\theta^{\prime}(-1)$ & $f^{\prime \prime}(-1)$ & $\theta^{\prime}(-1)$ \\
-25.0635 & -2.3717 & -19.9973 & -2.1652 & --- & --- \\
-3.4412 & -2.8153 & --- & --- & -3.49188 & -2.8161 \\
\hline
\end{tabular}

\section{RESULTS AND DISCUSSIONS}

The present study has been conducted to analyze the depiction of the flow behavior of hydromagnetic Casson fluid in a channel with stretching walls under the influence of second order velocity as well as thermal slips conditions. Results for fluid velocity as well as temperature profiles are presented graphically in Figures 2 to 6 for different cases, Case-1: no slip $\left(\lambda_{1}=\delta_{1}=\lambda_{2}=\delta_{2}=0\right)$, Case-2: only first order slip $\left(\lambda_{1}=\delta_{1}=0.1, \lambda_{2}=\delta_{2}=0\right)$ and Case- 3 : both first and second order slips $\left(\lambda_{1}=\delta_{1}=\lambda_{2}=\delta_{2}=0.1\right)$ for various physical parameters namely Casson fluid parameter $(\beta)$, Magnetic parameter $\left(\mathrm{M}^{2}\right)$ and thermal radiation parameter ( $\mathrm{Rd})$ and skin friction and Nusselt number results are reported in tabular form as well. Negative, zero, and positive values of the parameter $\lambda$ corresponds to injection, no cross flow and suction over the lower wall. The sway of different sundry physical parameters like Casson parameter $(\beta)$, Magnetic parameter $(\mathrm{M})$ and Radiation parameter $(\mathrm{Rd})$ for velocity and temperature profiles on sundry cases has been discussed in this section.

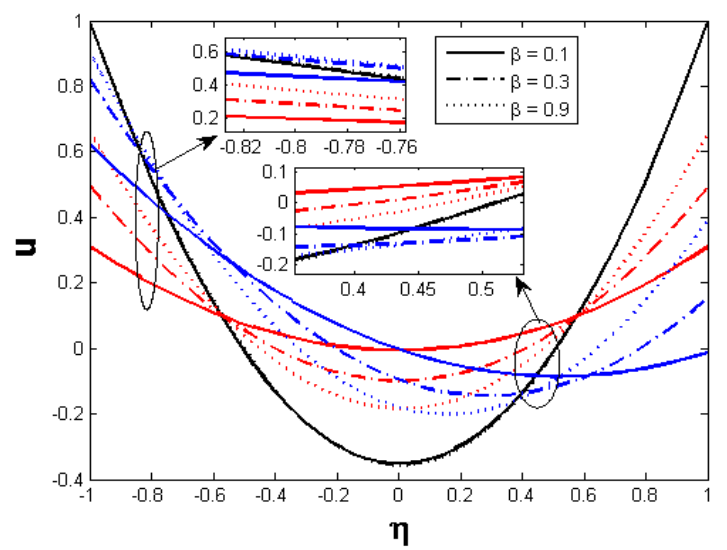

(a) $\lambda<0$

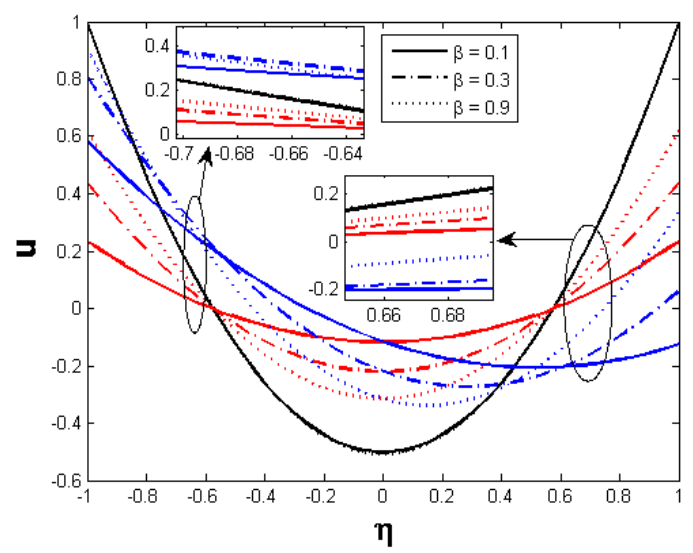

(b) $\lambda=0$ 


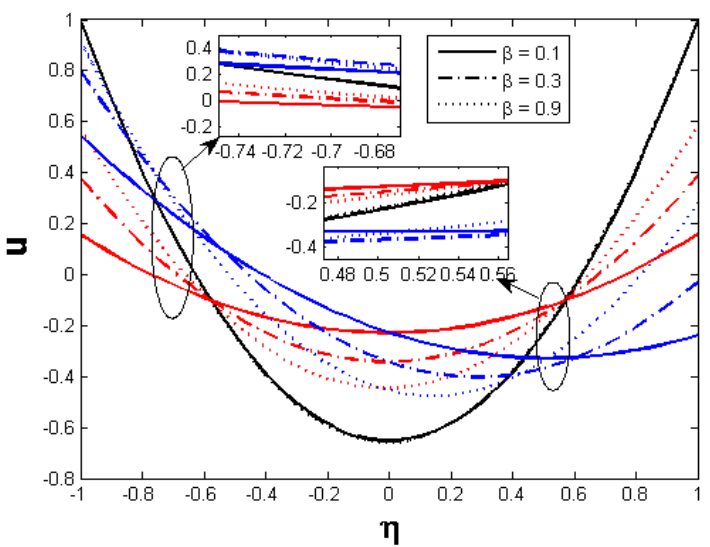

(c) $\lambda>0$

Figure 2. Velocity profile for Casson parameter with $\mathrm{Re}=1$, $\mathrm{Rd}=1, \mathrm{M} 2=1, \operatorname{Pr}=0.6$ on different cases: Case1: no slip (Black), Case2: only first order slips (Red) and Case3: both first and second order slips (Blue)

Figure 2 and 3 portrayed to discuss the influence of the Casson parameter on velocity and temperature profiles. Casson parameter $\beta=\mu \frac{\sqrt{2 \pi_{c}}}{p_{y}}$ means $\beta$ proportional to the ratio of dynamic viscosity and yield stress of the fluid. Increasing $\beta$ values implies either an increase in dynamic viscosity or reduction in yield stress of the fluid. It leads to enhance internal fluid resistance, and therefore, the fluid velocity enhanced near the stretched walls in all the three cases and reduced in the central region of the channel. It is also observed from this Figure 2 that drastic changes in fluid velocity for first and second order slips compare to no slip. It is also noted that an increase in $\lambda$ leads to retards the fluid velocity. As Casson parameter $\beta$ appears in momentum equation, fluid velocity increases in all the cases and therefore transfer of heat between fluid particles in the channel is less. Hence fluid temperature decreases markedly. Thus for all the three cases, an increase in $\beta$, depreciation of temperature is observed in the first half of the channel, and opposite results have been noted that is an enhancement of fluid temperature in the second half of the channel.

The impact of the magnetic parameter $(\mathrm{M})$ is demonstrated in Figures 4 and 5 . The magnetic parameter $M^{2}=\frac{\sigma}{\mu} B_{0}{ }^{2} a^{2}$ means ratio of magnetic strength and dynamic viscosity of the fluid. As M augments that is the strength of the magnetic field dominates the dynamic viscosity of the fluid, therefore, velocity of fluid enhances near the walls, and opposite results are noticed in the mid-region of the channel for the cases of no slip and first order slips. For second order slip, different behavior is noted in fluid velocity that is too opposite results of the fluid velocity over the channel has been observed from Figure 4. The fluid velocity and temperature get reduced slightly in the first half of the channel and enhanced in the second half of the channel for larger values of body force like magnetic force (M) for no slip and first order slip which is caused by no opposing force and less opposing force along the walls. But for second order slip cases opposing force on the fluid and temperature is more along the stretchable walls. Therefore, throughout the channel fluid temperature increased enormously with increase in Magnetic parameter(M) as shown in Figure 5.

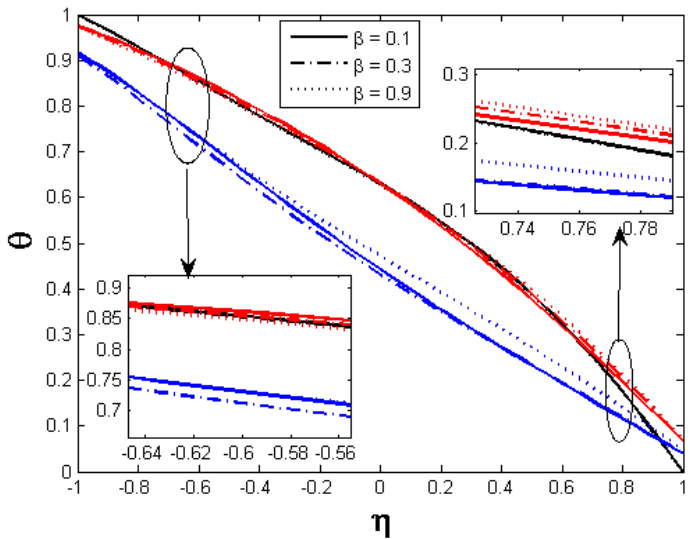

(a) $\lambda<0$

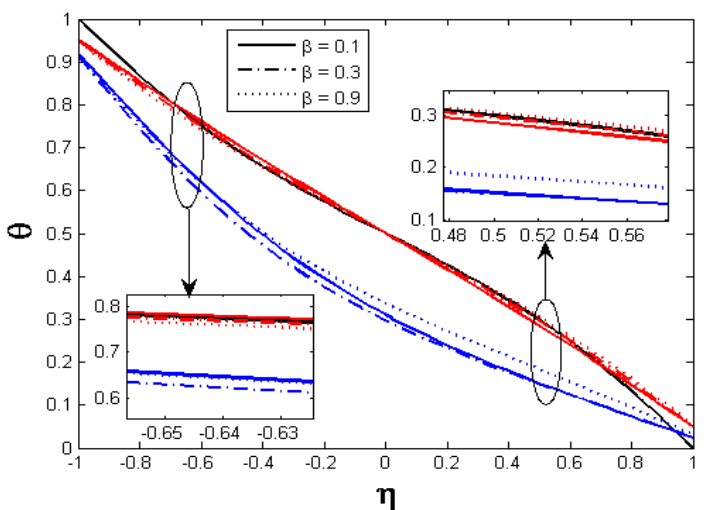

(b) $\lambda=0$

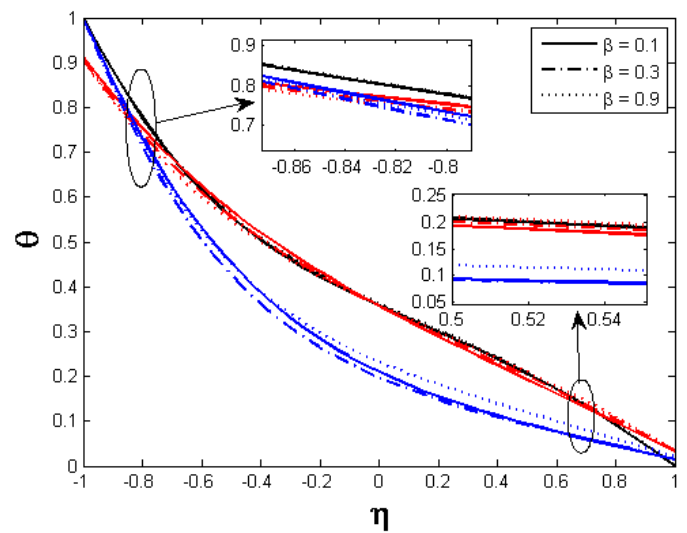

(c) $\lambda>0$

Figure 3. Temperature profile for Casson parameter with $\mathrm{Re}$ $=1, \mathrm{Rd}=1, \mathrm{M} 2=1, \operatorname{Pr}=0.6$ on different cases: Case $1:$ no slip (Black), Case2: only first order slips (Red) and Case3: both first and second order slips (Blue)

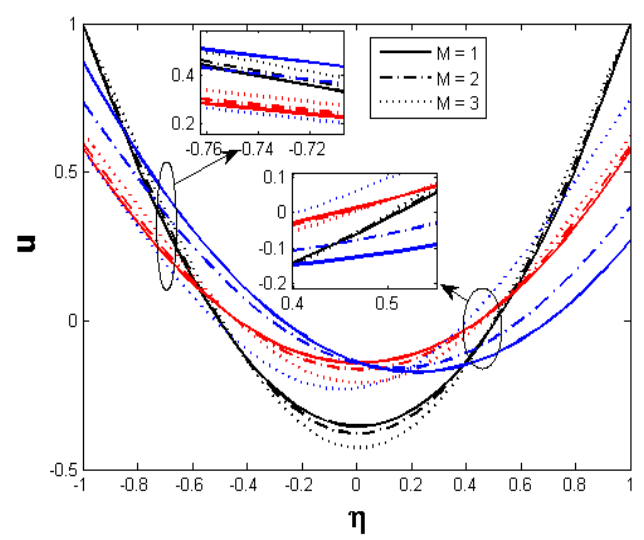

(a) $\lambda<0$ 


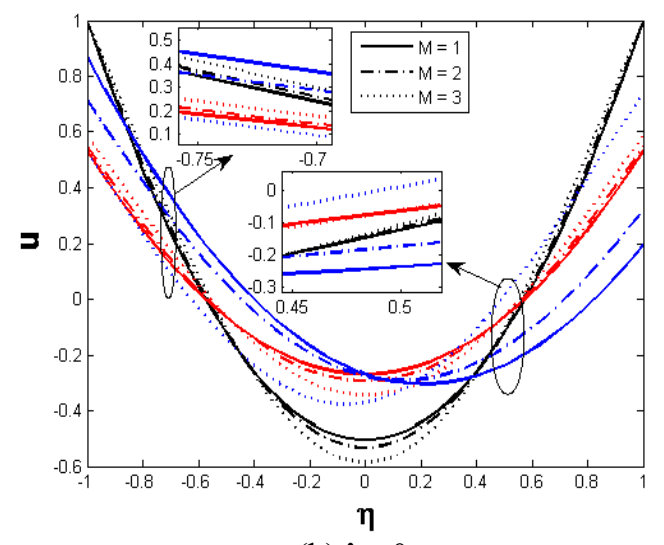

(b) $\lambda=0$

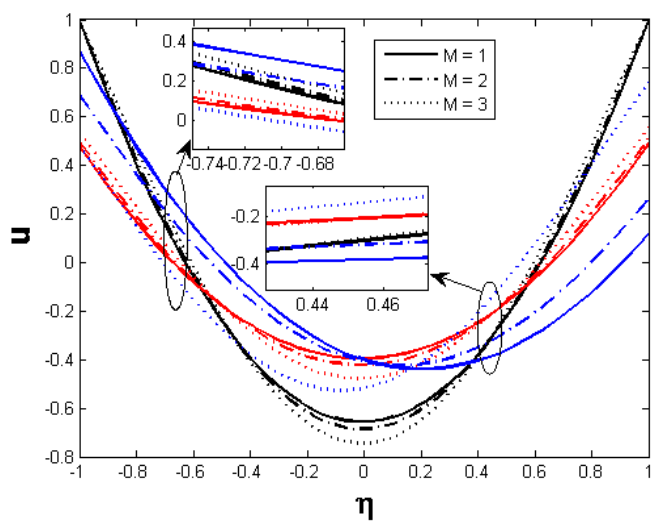

(c) $\lambda>0$

Figure 4. Velocity profile for Magnetic parameter with $\operatorname{Re}=1, \operatorname{Rd}=1, \beta=1, \operatorname{Pr}=0.6$ on different cases: Case 1: no slip (Black), Case2: only first order slips (Red) and Case3: both first and second order slips (Blue)

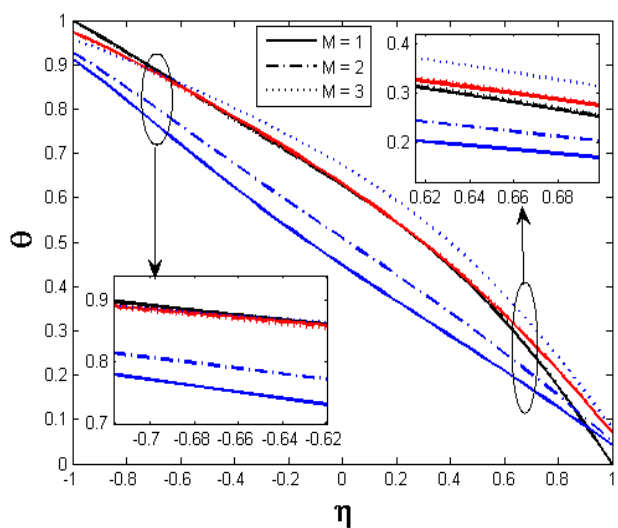

(a) $\lambda<0$

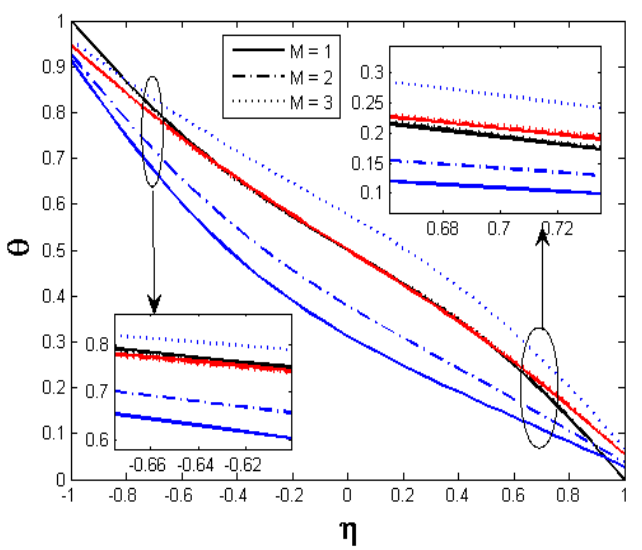

(b) $\lambda=0$

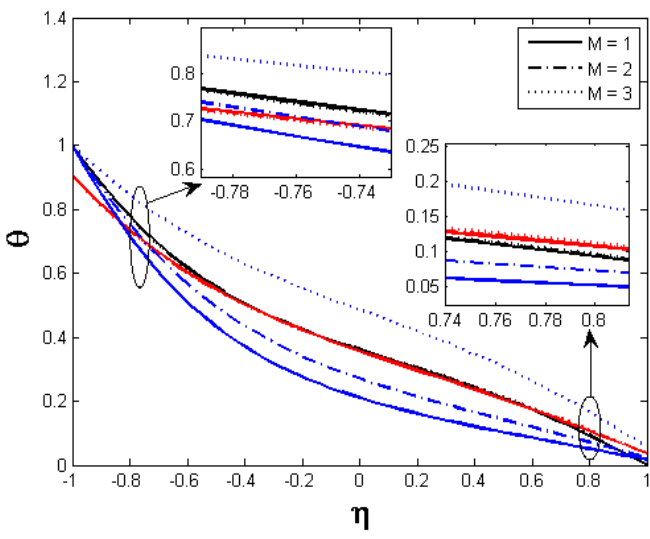

(c) $\lambda>0$

Figure 5. Temperature profile for Magnetic parameter with $\operatorname{Re}=1, \operatorname{Rd}=1, \beta=1, \operatorname{Pr}=0.6$ on different cases: Case 1: no slip (Black), Case2: only first order slips (Red) and Case3: both first and second order slips (Blue)

Figure 6 displays the impact of the radiation parameter $(\mathrm{Rd})$ on the temperature profiles. It is worth to mention that $\mathrm{Rd}$ enhances the heat transfer through the emission of internal energy, so temperature profiles also enhance the entire channel. As $\mathrm{Rd}$ improves, different behavior is observed on the temperature profile for $\lambda<0, \lambda=0$ and $\lambda>0$ for different three cases. An increase in Rd accelerates the fluid temperature for the case of second order slip for $\lambda<0, \lambda=0$ and $\lambda>0$ due to more heat transfer between fluid particles in the channel caused by the decrement of fluid velocity. The fluid temperature produces opposite results for $\lambda<0$, and $\lambda>0$ in the case of no slip and first order slips. That is fluid temperature is decreased for $\lambda<0$ and increased for $\lambda>0$ throughout the channel. But for $\lambda=0$, an increase in $\mathrm{Rd}$ fluid temperature gets increased over first and decreased over the second half of the channel, as shown in Figure 6.

Skin friction and rate of heat transfer (Nusselt number) over the walls for $\lambda<0, \lambda=0$ and $\lambda>0$ for different three cases have been reported in Tables 3 to 5 . For $\lambda<0, \lambda=0$ and $\lambda>0$, as $\beta$ increases the skin friction coefficient increases at the lower wall and decreases at the upper wall for no slip and first order slip cases due to influence of less viscosity. In the case of second order slip for $\lambda=0$ and $\lambda>0$, the skin friction coefficient increases for small values of $\beta$ and decreases for larger values of $\beta$ due to more opposing force and yield stress of the fluid. Therefore $\mathrm{Nu}$ increases with increment in $\beta$ at the both the walls for first and second order slip. but for no slip effect, $\mathrm{Nu}$ increases at the lower wall and decreases at the upper wall for $\lambda<0$ due to increment of the amount of fluid caused by injecting fluid. The exactly opposite trend is noted in no slip case for $\lambda>0$ due to decrement of the amount of the fluid caused by suctioning the fluid.

For no slip condition as $\mathbf{M}$ augments. skin friction coefficient increases at the lower wall and decreases at the upper wall in all the cases for $\lambda<0, \lambda=0$ and $\lambda>0$. In the case of first order slip as $\mathrm{M}$ increases skin friction coefficient decrease at both the walls, but for first and second order slip cases it increases at the lower wall and decreases at the upper wall due to less influence of magnetic field dominated by the opposing force. For $\lambda<0$, Nusselt number increase at both walls. For no slip and first order as well as second order slip, Nu decrease at the lower wall and increase at the upper wall. Similar behavior is observed for $\lambda=0$ and $\lambda>0$. 


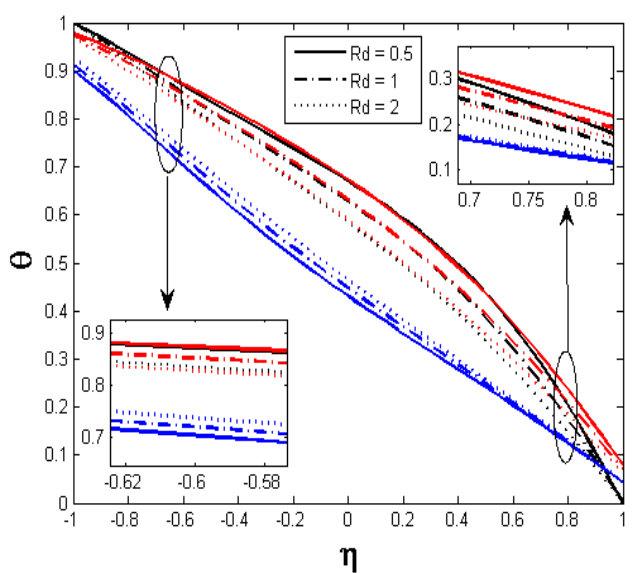

(a) $\lambda<0$

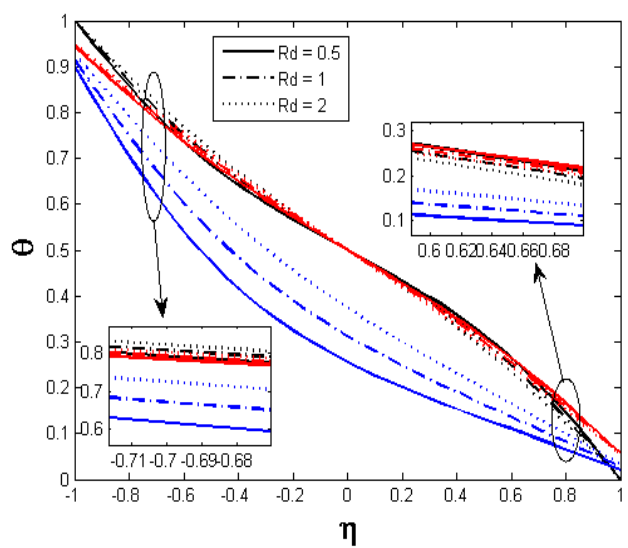

(b) $\lambda=0$

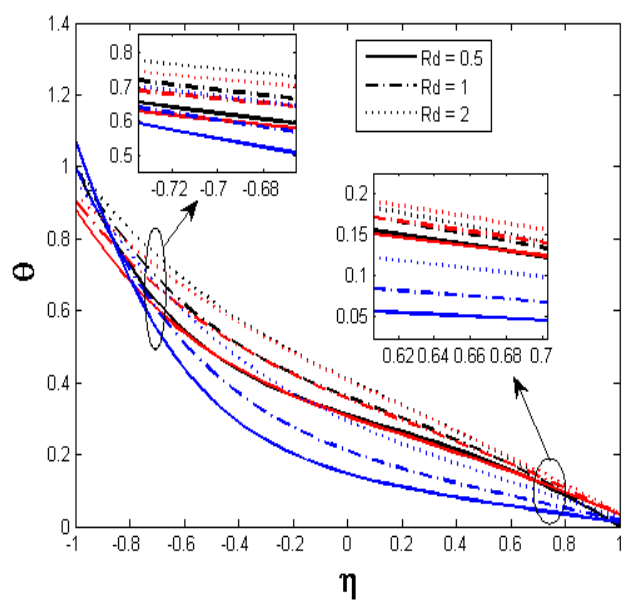

(c) $\lambda>0$

Figure 6. Temperature profile for Radiation parameter with $\operatorname{Re}=1, \operatorname{M} 2=1, \beta=1, \operatorname{Pr}=0.6$ on different cases: Case1: no slip (Black), Case2: only first order slips (Red) and Case3: both first and second order slips (Blue)

As $\mathrm{Rd}$ improves for $\lambda<0$, the heat transfer coefficient increases at the lower wall and decreases at the upper wall in the case of no slip and first order slip cases. As discussed earlier for second order slip that is more opposing force on fluid flow and temperature, $\mathrm{Nu}$ increases at both the walls due to more thermal radiation. For $\lambda=0, \mathrm{Nu}$ decrease at both the walls in no slip and first slip cases. But for second slip, $\mathrm{Nu}$ decreases at the lower wall and increases at the upper wall. For $\lambda>0, \mathrm{Nu}$ decreases at the lower wall and increases at the upper wall for all three cases.
Table 3. Skin friction and Nusselt number for $\lambda<0$

\begin{tabular}{|c|c|c|c|c|c|c|}
\hline \multicolumn{7}{|c|}{ No Slip } \\
\hline$\beta$ & M & Rd & $f^{\prime \prime}(-1)$ & $f^{\prime \prime}(1)$ & $\theta^{\prime}(-1)$ & $\theta^{\prime}(1)$ \\
\hline 0.1 & 1 & 1 & -29.4993 & 29.6793 & 0.3298 & 0.8916 \\
\hline 0.3 & & & -11.4990 & 11.6792 & 0.3318 & 0.8893 \\
\hline 0.9 & & & -5.4985 & 5.6790 & 0.3353 & 0.8852 \\
\hline \multirow[t]{3}{*}{0.5} & 1 & 1 & -7.8988 & 8.0791 & 0.3332 & 0.8876 \\
\hline & 2 & & -7.3271 & 7.5214 & 0.3365 & 0.8938 \\
\hline & 3 & & -6.2833 & 6.5116 & 0.3430 & 0.9049 \\
\hline \multirow[t]{3}{*}{0.5} & 1 & 0.5 & -7.8988 & 8.0791 & 0.2840 & 1.0486 \\
\hline & & 1.0 & -7.8988 & 8.0791 & 0.3332 & 0.8876 \\
\hline & & 2.0 & -7.8988 & 8.0791 & 0.3860 & 0.7423 \\
\hline \multicolumn{7}{|c|}{ First Order Slip } \\
\hline 0.1 & 1 & 1 & -6.8879 & 6.9082 & 0.2414 & 0.6532 \\
\hline 0.3 & & & -5.0306 & 5.0863 & 0.2568 & 0.6873 \\
\hline 0.9 & & & -3.3914 & 3.4841 & 0.2724 & 0.7160 \\
\hline \multirow[t]{3}{*}{0.5} & 1 & 1 & -4.1859 & 4.2602 & 0.2645 & 0.7024 \\
\hline & 2 & & -4.0138 & 4.1041 & 0.2678 & 0.7072 \\
\hline & 3 & & -3.6602 & 3.7996 & 0.2758 & 0.7154 \\
\hline \multirow[t]{3}{*}{0.5} & 1 & 0.5 & -4.1859 & 4.2602 & 0.2162 & 0.7952 \\
\hline & & 1.0 & -4.1859 & 4.2602 & 0.2645 & 0.7024 \\
\hline & & 2.0 & -4.1859 & 4.2602 & 0.3202 & 0.6140 \\
\hline \multicolumn{7}{|c|}{ Second order slip } \\
\hline 0.1 & 1 & 1 & -10.1462 & 3.3218 & 0.4098 & 0.3844 \\
\hline 0.3 & & & -6.3509 & 3.5977 & 0.4443 & 0.3922 \\
\hline 0.9 & & & -3.8848 & 2.9134 & 0.4157 & 0.4701 \\
\hline \multirow[t]{3}{*}{0.5} & 1 & 1 & -5.0112 & 3.3242 & 0.4347 & 0.4254 \\
\hline & 2 & & -4.0502 & 3.4808 & 0.3650 & 0.5139 \\
\hline & 3 & & -3.8968 & 3.9875 & 0.2147 & 0.8102 \\
\hline \multirow[t]{3}{*}{0.5} & 1 & 0.5 & -5.0112 & 3.3242 & 0.4278 & 0.4157 \\
\hline & & 1.0 & -5.0112 & 3.3242 & 0.4347 & 0.4254 \\
\hline & & 2.0 & -5.0112 & 3.3242 & 0.4414 & 0.4351 \\
\hline
\end{tabular}

Table 4. Skin friction and Nusselt number for $\lambda=0$

\begin{tabular}{|c|c|c|c|c|c|c|}
\hline \multicolumn{7}{|c|}{ No Slip } \\
\hline$\beta$ & M & $\mathrm{Rd}$ & $f^{\prime \prime}(-1)$ & $f^{\prime \prime}(1)$ & $\theta^{\prime}(-1)$ & $\theta^{\prime}(1)$ \\
\hline 0.1 & 1 & 1 & -32.8852 & 32.8852 & 0.6817 & 0.6817 \\
\hline 0.3 & & & -12.8844 & 12.8844 & 0.6822 & 0.6822 \\
\hline 0.9 & & & -6.2164 & 6.2164 & 0.6831 & 0.6831 \\
\hline \multirow[t]{3}{*}{0.5} & 1 & 1 & -8.8838 & 8.8838 & 0.6825 & 0.6825 \\
\hline & 2 & & -8.2531 & 8.2531 & 0.6883 & 0.6883 \\
\hline & 3 & & -7.1052 & 7.1052 & 0.6994 & 0.6994 \\
\hline \multirow[t]{3}{*}{0.5} & 1 & 0.5 & -8.8838 & 8.8838 & 0.7491 & 0.7491 \\
\hline & & 1.0 & -8.8838 & 8.8838 & 0.6825 & 0.6825 \\
\hline & & 2.0 & -8.8838 & 8.8838 & 0.6186 & 0.6186 \\
\hline \multicolumn{7}{|c|}{ First Order Slip } \\
\hline 0.1 & 1 & 1 & -7.6646 & 7.6646 & 0.4873 & 0.4873 \\
\hline 0.3 & & & -5.6210 & 5.6210 & 0.5168 & 0.5168 \\
\hline 0.9 & & & -3.8209 & 3.8209 & 0.5437 & 0.5437 \\
\hline \multirow[t]{3}{*}{0.5} & 1 & 1 & -4.6931 & 4.6931 & 0.5305 & 0.5305 \\
\hline & 2 & & -4.5099 & 4.5099 & 0.5357 & 0.5357 \\
\hline & 3 & & -4.1420 & 4.1420 & 0.5462 & 0.5462 \\
\hline \multirow[t]{3}{*}{0.5} & 1 & 0.5 & -4.6931 & 4.6931 & 0.5567 & 0.5567 \\
\hline & & 1.0 & -4.6931 & 4.6931 & 0.5305 & 0.5305 \\
\hline & & 2.0 & -4.6931 & 4.6931 & 0.5047 & 0.5047 \\
\hline \multicolumn{7}{|c|}{ Second order slip } \\
\hline 0.1 & 1 & 1 & -11.3403 & 3.6983 & 0.8007 & 0.2447 \\
\hline 0.3 & & & -7.1800 & 4.0156 & 0.8669 & 0.2475 \\
\hline 0.9 & & & -4.4589 & 3.2435 & 0.8238 & 0.3147 \\
\hline 0.5 & 1 & 1 & -5.7053 & 3.7090 & 0.8542 & 0.2750 \\
\hline
\end{tabular}




\begin{tabular}{l|l|l|l|l|l|l}
\hline & 2 & & -4.6118 & 3.8804 & 0.7303 & 0.3586 \\
\hline & 3 & & -4.5135 & 4.4442 & 0.4393 & 0.6785 \\
\hline 0.5 & 1 & 0.5 & -5.7053 & 3.7090 & 1.0083 & 0.2224 \\
\hline & & 1.0 & -5.7053 & 3.7090 & 0.8542 & 0.2750 \\
\hline & & 2.0 & -5.7053 & 3.7090 & 0.7078 & 0.3325 \\
\hline
\end{tabular}

Table 5. Skin friction and Nusselt number for $\lambda>0$

\begin{tabular}{|c|c|c|c|c|c|c|}
\hline \multicolumn{7}{|c|}{ No Slip } \\
\hline$\beta$ & M & Rd & $f^{\prime \prime}(-1)$ & $f^{\prime \prime}(1)$ & $\theta^{\prime}(-1)$ & $\theta^{\prime}(1)$ \\
\hline 0.1 & 1 & 1 & -36.2937 & 36.0727 & 1.2656 & 0.4688 \\
\hline 0.3 & & & -14.2937 & 14.0710 & 1.2615 & 0.4722 \\
\hline 0.9 & & & -6.9603 & 6.7348 & 1.2541 & 0.4784 \\
\hline \multirow[t]{3}{*}{0.5} & 1 & 1 & -9.8937 & 9.6698 & 1.2584 & 0.4748 \\
\hline & 2 & & -9.2053 & 8.9636 & 1.2671 & 0.4798 \\
\hline & 3 & & -7.9574 & 7.6722 & 1.2827 & 0.4899 \\
\hline \multirow[t]{3}{*}{0.5} & 1 & 0.5 & -9.8937 & 9.6698 & 1.6286 & 0.4439 \\
\hline & & 1.0 & -9.8937 & 9.6698 & 1.2584 & 0.4748 \\
\hline & & 2.0 & -9.8937 & 9.6698 & 0.9474 & 0.4946 \\
\hline \multicolumn{7}{|c|}{ First Order Slip } \\
\hline 0.1 & 1 & 1 & -8.4437 & 8.4187 & 0.8813 & 0.3261 \\
\hline 0.3 & & & -6.2183 & 6.1494 & 0.9292 & 0.3484 \\
\hline 0.9 & & & -4.2632 & 4.1472 & 0.9681 & 0.3714 \\
\hline \multirow[t]{3}{*}{0.5} & 1 & 1 & -5.2100 & 5.1176 & 0.9499 & 0.3597 \\
\hline & 2 & & -5.0177 & 4.9050 & 0.9562 & 0.3648 \\
\hline & 3 & & -4.6426 & 4.4666 & 0.9663 & 0.3770 \\
\hline \multirow[t]{3}{*}{0.5} & 1 & 0.5 & -5.2100 & 5.1176 & 1.1682 & 0.3200 \\
\hline & & 1.0 & -5.2100 & 5.1176 & 0.9499 & 0.3597 \\
\hline & & 2.0 & -5.2100 & 5.1176 & 0.7569 & 0.3962 \\
\hline \multicolumn{7}{|c|}{ Second order slip } \\
\hline 0.1 & 1 & 1 & -12.5493 & 4.0764 & 1.4976 & 0.1489 \\
\hline 0.3 & & & -8.0414 & 4.4377 & 1.6206 & 0.1494 \\
\hline 0.9 & & & -5.0767 & 3.5757 & 1.5653 & 0.2020 \\
\hline \multirow[t]{3}{*}{0.5} & 1 & 1 & -6.4381 & 4.0977 & 1.6086 & 0.1701 \\
\hline & 2 & & -5.2041 & 4.2830 & 1.3998 & 0.2405 \\
\hline & 3 & & -5.1792 & 4.9034 & 0.8711 & 0.5583 \\
\hline \multirow[t]{3}{*}{0.5} & 1 & 0.5 & -6.4381 & 4.0977 & 2.2691 & 0.1135 \\
\hline & & 1.0 & -6.4381 & 4.0977 & 1.6086 & 0.1701 \\
\hline & & 2.0 & -6.4381 & 4.0977 & 1.1076 & 0.2477 \\
\hline
\end{tabular}

\section{CONCLUSIONS}

In this article, a mathematical model has been developed to analyze multiple slip effects on MHD Casson fluid in a channel with stretchable walls. The governing non-linear partial differential equations are transformed into ordinary differential equations by using suitable transformations and then solved numerically by the Runge-Kutta shooting method. Main conclusions of the present study are:

- An improvement in $\beta$ enhances the velocity of the fluid near the walls, but the reverse trend is noted in the central region of the channel for all three cases no slip, first order and second order slip. It is also noted that an increase in $\lambda$, velocity of fluid decelerates in the entire channel. As $\beta$ increases, the fluid temperature decline in the first half and improves in the second half of the channel for all the cases.

- An improvement in $\mathrm{M}$ causes the reduction in velocity of fluid in first half and enhancement in second half of the channel for the second order slip effects.

- As Rd enhances the temperature of fluid for $\lambda<0, \lambda=0$ and $\lambda>0$ improve in the case of second order slip but opposite trend is noted for $\lambda<0$ and $\lambda>0$ for no slip and first order slip cases.

- As $\mathrm{Rd}$ improves for $\lambda<0$ and $\lambda>0$ Nusselt number increases at lower wall and decreases at upper wall in all three cases. For $\lambda=0, \mathrm{Nu}$ will decrease at lower wall for no slip and first order slip but for second slip it decreases at lower wall and increases at upper wall.

- As $\mathrm{M}$ and $\beta$ enhances, the skin friction coefficient increases at lower wall and decreases at upper wall in no slip and first slip cases but it improves at both the walls in second slip case for $\lambda<0, \lambda=0$ and $\lambda>0$.

\section{REFERENCES}

[1] Casson, N. (1959). A flow equation for pigment oil suspensions of the printing ink type. In Rheology of Dispersed System; Mill, C.C., Ed.; Pergamon Press: Oxford, UK, 84-102.

[2] Shehzad, S.A., Hayat, T., Qasim, N., Asghar, S. (2013). Effects of mass transfer on MHD flow of Casson fluid with chemical reaction and suction. Branilian Journal of Chemical Engineering, 30(1): 187-195. http://dx.doi.org/10.1590/S0104-66322013000100020

[3] Hayat, T., Farooq. M., Alsaedi, A. (2015). Thermally stratified stagnation point flow of Casson fluid with slip conditions. International Journal of Numerical Methods for Heat and Fluid Flow, 25(4): 724-748. 10.1108/HFF05-2014-014

[4] Mabood, F., Khan, W.A., Ismail, A.I.M. (2015). Multiple slips effects on MHD Casson fluid flow in porous media with radiation and chemical reaction. Canadian Journal of Physics, 93(1): 1-9. https://doi.org/10.1139/cjp-20140667

[5] Akbar, N.S., Tripathi, D., Anwar Beg, O., Khan, Z.H. (2016). MHD dissipative flow and heat transfer of Casson fluids due to metachronal wave propulsion of beating cilia with thermal and velocity slip effects under an oblique magnetic field. Acta Astronautica, 128: 1-12. http://dx.doi.org/10.1016/j.actaastro.2016.06.044

[6] Ullah, I., Shafie, S., Khan, I. (2017). Effects of slip condition and Newtonian heating on MHD flow of Casson fluid over a nonlinearly stretching sheet saturated in a porous medium. Journal of King Saud UniversityScience, 29(2): http://dx.doi.org/10.1016/j.jksus.2016.05.003

[7] Gudekote, M., Choudhari, R. (2018). Slip effects on Peristaltic transport of Casson fluid in an inclined elastic tube with porous walls. Journal of Advanced Research in Fluid Mechanics and Thermal Sciences, 43(1): 67-80. http://www.akademiabaru.com/doc/ARFMTSV43_N1_ P67_80.pdf.

[8] Hayat, T., Shehzad, S.A., Alsaedi, A., Alhothuli, M.S. (2012). Mixed convective stagnation point flow of Casson fluid with convective boundary condition. Chinese Physics Letters, 29(11): 256-307. https://doi.org/10.1088/0256-307X/29/11/114704

[9] Nadeem, S., Haq, R. U., Lee, C. (2012). MHD flow of a Casson fluid over an exponentially shrinking sheet. Scientia Iranica, 19(6): 1550-1553. https://doi.org/10.1016/j.scient.2012.10.021

[10] Bhattacharyya, K., Hayat, T., Alsaedi, A. (2013). Analytic solution for magnetohydrodynamic boundary layer flow of Casson fluid over a stretching/shrinking 
sheet with wall mass transfer. Chinese Physics B, 22(2): 024702 .

https://doi.org/10.1088/1674-1056/22/2/024702

[11] Nadeem, S., Haq, R.U., Akbar, N.S., Khan, Z.H. (2013). MHD three-dimensional Casson fluid flow past a porous linearly stretching sheet. Alexandria Engineering Journal, 52(4):

$577-582$ https://doi.org/10.1016/j.aej.2013.08.005

[12] Bhattacharyya, K. (2013). Boundary layer stagnationpoint flow of Casson fluid and heat transfer towards a shrinking/stretching sheet. Frontiers Heat Mass Transfer (FHMT), 4:

023003. https://doi.org/10.5098/hmt.v4.2.3003

[13] Mukhopadhyay, S. (2013). Effects of thermal radiation on Casson fluid flow and heat transfer over an unsteady stretching surface subjected to suction/blowing. Chinese $\begin{array}{llll}\text { Physics } & \text { B, } & 22(11): & 114702 .\end{array}$ https://doi.org/10.1088/1674-1056/22/11/114702

[14] Parmanik, S. (2014). Casson fluid flow and heat transfer past an exponential porous stretching surface in presence of thermal radiation. Ain Shams Engineering Journal, $5(1)$ : 205-212. https://doi.org/10.1016/j.asej.2013.05.003

[15] Makanda, G. (2015). Diffusion of chemically reactive species in casson fluid flow over an unsteady stretching surface in porous medium in the presence of a magnetic field. Hindawi Publishing Corporation Mathematical Problems in Engineering, 2015: 724596. http://dx.doi.org/10.1155/2015/724596

[16] Khan, M.I., Waqas, M., Hayat, T., Alsaedi, A. (2017). Colloidal study of Casson fluid with homogeneousheterogeneous reactions. Journal of Colloid and Interface Science, 498:

85-90. https://doi.org/10.1016/j.jcis.2017.03.024

[17] Das, S., Mondal, H., Kumar Kundu, P., Sibanda, P. (2018). Spectral quasi-linearization method for Casson fluid with homogeneous heterogeneous reaction in presence of nonlinear thermal radiation over an exponential stretching sheet. Multidiscipline Modeling in Materials and Structures, 15(2): 398-417. https://doi.org/10.1108/MMMS-04-2018-0073

[18] Nagendramma, V., Raju, C.S.K., Mallikarjuna, B., Shehzad, S.A., Leelarathnam, A. (2018). 3D casson nanofluid flow over slandering surface in a suspension of gyrotactic microorganisms with Cattaneo-Christov heat flux. Applied Mathematics and Mechanics, 39: 623-638. https://doi.org/10.1007/s10483-018-2331-6

[19] Hamid, M., Usmanb, M., Khane, Z.H., Ahmadg, F.R., Wanga, W. (2019). Dual solutions and stability analysis of flow and heat transfer of Casson fluid over the stretching sheet. Physics Letters A, 383(20): 1-9. https://doi.org/10.1016/j.physleta.2019.04.050

[20] Mahantesh, M.N., Vajravelu, K., Subhas Abel, M., Siddalingappa, M.N. (2012). Second order slip flow and heat transfer over a stretching sheet with non-linear Navier boundary condition. International Journal of Thermal Sciences, 58: 143-150. https://doi.org/10.1016/j.ijthermalsci.2012.02.019

[21] Rosca, A.V., Pop, I. (2013). Flow and heat transfer over a vertical permeable stretching/shrinking sheet with a second order slip. International Journal of Heat and Mass Transfer, 60: 355-364. https://doi.org/10.1016/j.ijheatmasstransfer.2012.12.028

[22] Mansur, S., Ishak, A. (2014). The magnetohydrodynamic boundary layer flow of a nanofluid past a stretching/shrinking sheet with slip boundary conditions. Journal of Applied Mathematics, 2014: 907152. http://dx.doi.org/10.1155/2014/907152

[23] Jing, Z., Zheng, L., Zheng, L., Zhang, X. (2015). Secondorder slip MHD flow and heat transfer of nanofluids with thermal radiation and chemical reaction. Applied Mathematics and Mechanics, 36: 1131-1146. https://doi.org/10.1007/s10483-015-1977-6

[24] Hsiao, K.L. (2016). Stagnation electrical MHD nanofluid mixed convection with slip boundary on a stretching sheet. Applied Thermal Engineering, 98: 850-861. https://doi.org/10.1016/j.applthermaleng.2015.12.138

[25] Shashikumar, N.S., Archana, M., Prasannakumara, B.C., Gireesha, B.J., Makinde, O.D. (2017). Effects of nonlinear thermal radiation and second order slip on Casson nanofluid flow between parallel plates. Defect and Diffusion Forum, 377: 84-94. https://doi.org/10.4028/www.scientific.net/DDF.377.84

[26] Rosca, A.V., Rosca, N.V., Pop, I. (2018). Stagnation point flow of a nanofluid past a non-aligned stretching/shrinking heat with a second-order slip velocity. International Journal of Numerical Methods for Heat \& Fluid Flow, 29(2): 738-726. https://doi.org/10.1108/HFF-05-2018-0201

[27] Balaanki Reddy, P., Mallikarjuna, B., Madhusudhan Reddy, K. (2018). Slip effect on heat and mass transfer in a Casson fluid with Cattaneo-Christove heat flux model. Frontiers in Heat and Mass Transfer, 11(5). https://doi.org/10.5098/hmt.11.5

[28] Vishnu Ganesh, V., Qasem, M., Al-Mdallal, Chamkha, A.J. (2019). A numerical investigation of Newtonian fluid flow with buoyancy thermal slip of order two and entropy generation. Case Studies in Thermal Engineering, 13: 100376. https://doi.org/10.1016/j.csite.2018.100376

[29] Shahid, A.K., Nie, Y., Ali, B. (2019). Multiple slip effects on magnetohydrodynamic axisymmetric buoyant nanofluid flow above a stretching sheet with radiation and chemical reaction. Symmetry, 11(9): 1171. https://doi.org/10.3390/sym11091171

[30] Hayat, T., Qayyum, S., Alsaedi, A., Ahmad, B. (2020). Entropy generation minimization: Darcy-Forchheimer nanofluid flow due to curved stretching sheet with partial slip. International Communications in Heat and Mass Transfer, 111: 104445 . https://doi.org/10.1016/j.icheatmasstransfer.2019.10444 5

[31] Daniel, Y.S., Aziz, Z.A., Ismail, Z., Bahar, A., Salah, F. (2020). Slip role for unsteady MHD mixed convection of nanofluid over stretching sheet thermal radiation and electric field. Indian Journal of Physics, 94(2): 195-207. https://doi.org/10.1007/s12648-019-01474-y

[32] Misra, J.C., Shit, G.C., Rath, H.J. (2008). Flow and heat transfer of a MHD viscoelastic fluid in a channel with stretching walls: Some applications to haemodynamics.

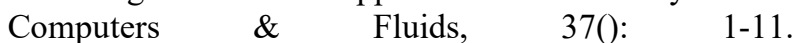
https://doi.org/10.1016/j.compfluid.2006.09.005

[33] Misra, J.C., Shit, G.C., Chandra, S., Kundu, P.K. (2011). Hydromagnetic flow and heat transfer of a second-grade viscoelastic fluid in a channel with oscillatory stretching walls: Application to the dynamics of blood flow. Journal of Engineering Mathematics, 69: 91-100. https://doi.org/10.1007/s10665-010-9376-X

[34] Ramanamurthy, J.V., Prasad, K.M., Narla, V.K. (2013). 
Unsteady peristaltic transport in curved channels. Physics of Fluids, 25: 091903. https://doi.org/10.1063/1.4821355

[35] Ghosh, S.K., Shit, G.C., Misra, J.C. (2014). Heat transfer in hydromagnetic fluid flow: Study of temperature dependence of fluid viscosity. Journal of Applied Fluid Mechanics, 7: 633-640.

[36] Sarojamma, G., Vasundhara, B. (2014). MHD Casson fluid flow, heat and mass transfer in a vertical channel with stretching walls. International Journal of Scientific and Innovative Mathematical Research, 2(10): 800-810.

[37] Mohyud-Din, S.T., Khan, U., Ahmed, N., Hassan, S.M. (2015). Magnetohydrodynamic flow and heat transfer of nanofluids in stretchable convergent/divergent channels. Appl. Sci., 5(4): 1639-1664. https://doi.org/10.3390/app5041639

[38] Rauf, A., Shahzad, S.A., Siddiq, M.K., Raza. J., Meraj, M.A. (2016). Mixed convective thermally radiative micro nanofluid flow in a stretchable channel with porous medium and magnetic field. AIP Advances, 6: 035126. https://doi.org/10.1063/1.4945369

[39] Raza, J., Rohni, A.M., Omar, Z. (2016). Numerical investigation of copper-water (cu-water) nanofluid with different shapes of nanoparticles in a channel with stretching wall slip effects. Mathematical and Computational Applications, $21(4)$ : 43. https://doi.org/10.3390/mca21040043

[40] Reza, J., MebarekOudina, F., Makinde, O.D. (2018). MHD slip flow of $\mathrm{Cu}$-kerosene nanofluid in a channel with stretching walls using 3-stage Lobatto IIIA formula. Defect and Diffusion Forum, 387: 51-62. https://doi.org/10.4028/www.scientific.net/DDF.387.51

[41] Kezzar, M., Tabet, I., Nafir, N. (2019). Semi analytical and numerical solutions of nonlinear problem of unsteady squeezing ferro fluid flow between stretchable/ shrinkable walls under external magnetic field and thermal radiation using differential transformation method. Journal of Nanofluids, 8(2): 297-307(11). https://doi.org/10.1166/jon.2019.1599

[42] Zohra, F.T., Uddin, M.J., Ismail, A.I.M. (2019). Magnetodytrodynamic bio-nanoconvective Naiver slip flow of micropolar fluid in a stretchable horizontal channel. Heat Transfer, 48(8): 3636-363656. https://doi.org/10.1002/htj.21560

[43] Ashraf, M., Jameel, N., Ali, K. (2013). MHD nonNewtonian micropolar fluid flow and heat transfer in channel with stretching walls. Applied Mathematics and Mechanics, 34: 1263-1276. https://doi.org/10.1007/s10483-013-1743-7

[44] Raza, J., MohdRohni, A., Omar, Z. (2016). MHD flow and heat transfer of $\mathrm{Cu}-$-water nanofluid in a semi porous channel with stretching walls. International Journal of Heat and Mass Transfer, 103: 336-340. https://doi.org/10.1016/j.ijheatmasstransfer.2016.07.064

[45] Jain, M.K., Iyengar, S.R.K., Jain, R.K. (2012). Numerical Methods for Scientific and Engineering Computation. Sixth Edition, New Age International Publishers.

[46] Rashad, A.M., Mallikarjuna, B., Chamkha, A.J., Hariprasad Raju, S. (2016). Thermophoresis effect on heat and mass transfer from a rotating cone in a porous

medium with thermal radiation. Afrika Matematika, 27(7-8): 1409-1424. https://doi.org/10.1007/s13370016-0421-4

\section{NOMENCLATURE}

$\bar{B}$

$\bar{b}$

$f$

$u, v$

$v$

$B_{o}$

$\mu_{B}$

$\tau_{i j}$

$P_{y}$

$\pi_{c}$

$\operatorname{Re}$

$R d$

$S c$

$\mathrm{Pr}$

$M^{2}$

$\lambda_{1}$

$\lambda_{2}$

$\delta_{1}$

$\delta_{2}$

$C_{f}$

$\mathrm{Nu}$

$T$

$T_{1}$

$T_{2}$

$C_{1}$

$C_{2}$

$q_{w}$

$\tau_{w}$

C

$a, b$

$T_{\infty}$

$\sigma^{*}$

$k^{*}$

$D$

$C_{p}$

$k$

$e_{i j}$

fluid velocity

total magnetic field

magnetic field

force function

velocity component along $x$ - and $y$-direction

kinematic viscosity

electrical conductivity

magnetic field strength

dynamic viscosity of the Casson fluid

Cauchy stress tensor

yield stress of the fluid

critical value of $\pi$

Reynolds number

Radiation parameter

Schmidt number

Prandtl number

magnetic parameter

first order hydrodynamic slip condition along walls

second order hydrodynamic slip condition along walls

first order thermal slip condition along walls second order thermal slip condition along walls skin friction coefficient nusselt number temperature

first order temperature slip condition along walls second order temperature slip condition along walls

first order concentration slip condition along walls second order concentration slip condition along walls

heat flux

skin shear stress on the wall

casson fluid concentration

constants

temperature far away from the wall

Stefan-Boltzmann coefficient

mean absorption coefficient

mass diffusivity

specific heat coefficient

thermal conductivity

$(i, j)$ th component of deformation rate

\section{Greek symbols}

$\mu$

$\beta$

$\theta$

$\varphi$

$\eta$

$\pi$

$\rho$ kinematic viscosity of the fluid casson fluid parameter dimensionless temperature dimensionless concentration dimensionless variable square of components of strain rate fluid density 